\title{
ANALISA KEPUASAN MAHASISWA TERHADAP SISTEM INFORMASI PERPUSTAKAAN UNIVERSITAS MERDEKA MADIUN MENGGUNAKAN FRAMEWORK PIECES
}

\author{
Nanang Junaedi \\ Program Studi D3 Manajemen Informatika \\ Universitas Merdeka Madiun \\ e-mail: ang.jun.1@gmail.com
}

\begin{abstract}
Abstrak-Kepuasan pengguna Sistem Informasi adalah tolak ukur baik tidaknya sebuah Sistem Informasi. Proses pengukuran SI dapat dilakukan dengan banyak cara. Dalam penelitian ini akan dilakukan proses pengukuran Perpustakaan Universitas Merdeka Madiun dengan PIECES Framework. Perkembangan teknologi informasi idealnya memudahkan berbagai pekerjaan di perpustakaan yang membuat pustakawan menjadi lebih efektif dan efisien dalam menyelesaikan tugas-tugasnya. Metode analisis PIECES Framework, yang memiliki beberapa domain atau point analisa, diantaranya : Performance, Informations and Data, Economics, Control and Security, Efficiency, and Service. Pada setiap domain analisa adalah referensi untuk mengevaluasi dan menganalisa sistem informasi perpustakaan. Hasil dari penelitian ini menunjukkan bahwa sistem informasi perpustakaan Universitas Merdeka Madiun yang sedang digunakan telah memiliki beberapa kelebihan dan kekuatan yang dapat mendukung dalam kegiatan operasional perpustakaan.
\end{abstract}

Kata kunci-Sistem Informasi, Kepuasan, Perpustakaan, PIECES Framework.

\section{Pendahuluan}

Setiap organiasi harus mengidentifikasi kebutuhan akan informasi yang dijalankan secara sistematis serta melakukan analisis untuk misi dan fungsi yang dilakukan, siapa yang menggunakan, data dan informasi pendukung yang diperlukan untuk melakukan berbagai fungsi tugas dan proses yang dibutuhkan untuk struktur data informasi yang paling digunakan[1].

Peranan sistem informasi di segala bidang usaha sudah menjadi pendukung dalam kegiatan operasional keseharian perusahaan, Salah satunya sistem informasi perpustakaan, dari sekolah sampai dengan perguruan tinggi pasti memiliki. Saat ini perpustakaan merupakan sebagai pusat informasi dan sumber ilmu pengetahuan.[2] Sebagai pusat informasi, perpustakaan sudah diwajibkan untuk menggunakan sistem informasi untuk mengelola data dan informasi dalam kegiatan perpustakaan sehari-hari. Penggunaan sistem informasi memerlukan pengaturan dan pengelolaan yang bersifat khusus[3], sehingga sistem ini biasa disebut sebagai sistem informasi manajemen. Didalamnya terdapat berbagai kegiatan mulai dari perencanaan sistem, perawatan, sampai pengukuran kinerjanya.

Dalam menjalankan sistem informasi perpustakaan diperlukan perangkat lunak dan perangkat keras serta manusia sebagai operatornya. Komponen di atas harus saling berhubungan agar kegiatan perpustakaan dapat berjalan dengan baik dan lancar. Untuk mengetahui apakah komponen sistem informasi berjalan sebagaimana mestinya, mesti memerlukan proses evaluasi[4]. Dalam penelitian ini dilakukan kegiatan evaluasi terhadap sebuah sistem informasi perpustakaan untuk menilai apakah sistem informasi perpustakaan yang digunakan sudah dapat memenuhi kebutuhan para penggunanya yaitu petugas perpustakaan dan anggota perpustakaan[5].

Untuk mengetahui apakah sistem informasi perpustakaan Universitas Merdeka Madiun berjalan sebagaimana mestinya, maka diperlukan proses evaluasi terhadap kinerja dari sistem informasi tersebut. Evaluasi merupakan kegiatan terencana untuk menilai suatu permasalahan yang terjadi dengan menggunakan instrumen dan hasilnya dapat dibandingkan dengan tolok ukur untuk memperoleh kesimpulan sehingga ditemukan solusi untuk menyelesaikan permasalahan yang timbul. Sedangkan Evaluasi sistem informasi dapat dilakukan dengan cara yang berbeda dan pada tingkatan yang berbeda, tergantung pada tujuan evaluasinya. Tujuannya adalah untuk menilai kemampuan teknis, pelaksanaan operasional, dan pendayagunaan sistem[6].

Kepuasan pengguna merupaka rangkuman kondisi psikologis yang dihasilkan ketika emosi yang mengelilingi harapan tidak cocok oleh perasaan yang terbentuk mengenai pengalaman pengkonsumsian. Kepuasan pelanggan berarti terpenuhinya kebutuhan dan harapan para pelanggan selama masa pelayanan. Penggunaan teknologi seperti itu dalam bisnis dapat membantu perusahaan memperbaiki proses komunikasi dengan pelanggan. Selain itu, efisiensi dan efektivitas biaya dukungan online dapat meningkatkan kepuasan pelanggan karena layanan disediakan dan mudah diakses secara cepat dan selalu. Kunci utama retensi pelanggan adalah kepuasan pelanggan dan loyalitas yang sangat bergantung pada kualitas layanan yang ditawarkan. Untuk mempertahankan kesuksesan sebuah perusahaan, produk dan layanan penawaran pasar harus memenuhi kebutuhan dan kepuasan pelanggan atau bahkan untuk melampaui ekspektasi mereka[2]. 
Analisis tingkat kepuasan dan tingkat kepentingan sistem informasi Perpustakaan UNMER menitikberatkan pada bagaimana mengidentifikasi kelemahan yang dijumpai pada sistem. Dalam melakukan kegiatan analisis dan evaluasi sistem informasi terdapat beberapa metode atau model analisis yang dapat digunakan, salah satunya adalah model analisis PIECES Framework. PIECES Framework sendiri merupakan suatu alat dalam menganalisis sistem informasi yang berbasis komputer, dimana terdiri dari poin-poin penting yang berguna untuk dijadikan pedoman/acuan dalam menganalisis sistem tersebut. Secara singkat, PIECES Framework mengandung hal-hal penting dalam pengevaluasian sistem, seperti: Performance, Information and data, Economics, Control and security, Efficiency, dan yang terakhir Service[6].

Dengan menggunakan PIECES Framework sebagai alat analisis sistem, suatu sistem secara detail dan menyeluruh akan mendapat perhatian khusus, sehingga kekuatan dan kelemahan sistem dapat diketahui untuk nantinya dijadikan acuan bagi kemajuan perusahaan selanjutnya. Hasil analisis PIECES merupakan dokumen kelemahan sistem yang menjadi rekomendasi untuk perbaikan-perbaikan yang harus dibuat pada sistem yang akan dikembangkan lebih lanjut untuk perbaikan dari sistem sebelumnya.

\section{LANDASAN TEORI}

\section{PIECES FRAMEWORK}

PIECES Framework adalah kerangka yang dipakai untuk mengklasifikasikan suatu problem, opportunities, dan directives yang terdapat pada bagian scope definition analisa dan perancangan sistem. Dengan kerangka ini, dapat dihasilkan hal-hal baru yang dapat menjadi pertimbangan dalam pengembangan sistem. Setiap huruf dalam PIECES merepresentasikan sebuah kategori dalam perumusan masalah yang ada[7], yaitu :

$P($ Performance $)=$ kinerja sistem

I $($ Information $)=$ informasi yg disajikan

$\mathrm{E}($ Economics $)=$ keuntungan yg dapat diraih

$\mathrm{C}($ Control $)=$ keamanan sistem

E (Efficiency) $=$ efisiensi orang dan proses

$\mathrm{S}$ (Service) $=$ layanan yang diberikan

Pieces framework dapat dipakai sebagai alat untuk mengevaluasi sistem yang sekarang ada dan melihat peluang perbaikan.

Framework Pieces adalah Suatu daftar untuk mengidentifikasikan masalah dengan system informasi yang sudah ada.

\section{A. Performance}

- Throughput

- Waktu Respon

\section{B. Informasi dan Data}

- Outputs

○ Kekurangan informasi

- Kekurangan informasi yang dibutuhkan

- Kekurangan informasi yang berhubungan

- Kelebihan informasi

- Informasi yang bukan merupakan format yang berguna.

- Informasi yang tidak akurat

- Informasi yang sulit menghasilkan apapun

- Informasi yang tidak dipakai pada waktunya

- Inputs

- Data tidak dapat diambil

- Data tidak diambil pada waktunya untuk menjadi berguna

- Pengambilan data yang tidak akurat

- Data yang sulit untuk diperoleh

- Data kita yang telah diperoleh berlebihan

- Kebanyakan data yang diperoleh

- Data ilegal yang telah diperoleh

- Penyimpanan data

- Data yang telah disimpan secara berlebihan dalam basisdata

- Penyimpanan data yang tidak akurat

- Data yang tidak aman dari kecelakaan

- Data tidak diorganisir dengan baik

- Data tidak fleksibel

- Data tidak dapat diakses

\section{Economics}

- Costs

- Biaya yang tidak diketahui

- Biaya yang tidak terduga

- Biaya yang terlalu tinggi

- Profits

- Market baru bisa di jangkau

- Arus pemasaran yang bisa berkembang

\section{Control (and Security)}

- Terlalu sedikit keamanan atau pengawasan

- Penginputan data yang tidak cukup diubah

- Tindakan kiminalitas yang merusak data

- Etika yang dilanggar pada data atau informasi

- Kelebihan penyimpanan data yang tidak konsisten pada file atau basisata yang berbeda

- Peraturan data pribadi yang telah dilanggar

- Eror proses yang akan terjadi

- Eror pembuat keputusan yang terjadi 
- Terlalu ketatnya keamanan

- Birokrasi ketat yang akan menghambat sistem

- Pengawasan yang berlebihan membuat ketidaknyamanan pada pelanggan ataupun karyawan

- Pengawasan secara khusus yang menyebabkan penundaan pada proses

\section{E. Efficiency}

- Pengguna, mesin, atau computer

- Data yang secara berlebihan diinput atau di-copy

- Pemrosesan data yang secara berlebihan

- Informasi yang dihasilkan secara berlebihan

- People, machines, or computers waste materials and suppliers

- Usaha yang dibutuhkan untuk tugas yang belebihan

- Bahan baku yang dibutuhkan untuk tugas yang berlebihan

\section{F. Service}

- System menghasilkan hasil yang tidak akurat

- System menghasilkan hasil yang tidak konsisten

- System menghasilkan hasil yang tidak dapat dipercaya

- System tidak mudah untuk dipelajari

- System tidak mudah untuk digunakan

- System terlalu membingungkan untuk digunakan

- Sistem tidak fleksibel untuk situasi yang baru

- System tidak fleksibel untuk berubah

- System tidak cocok dengan system yang lain

- System tidak terkordinasi dengan system yang lain

\section{Sistem Informasi}

Sistem adalah suatu kumpulan atau himpunan dari unsur - unsur, komponen atau variable yang terorganisir, saling berintegrasi, saling berinteraksi, saling tergantung satu sama lain dan terpadu[8]. Sistem informasi adalah suatu sistem di dalam suatu organisasi yang mempertemukan kebutuhan pengolahan transaksi harian, mendukung operasi, bersifat manajerial dan kegiatan strategi dari suatu organisasi dan menyediakan pihak luar tertentu dengan laporanlaporan yang diperlukan[9]. Sistem informasi secara teknis dapat didefinisikan sebagai sekumpulan komponen yang saling berhubungan, mengumpul kan atau mendapatkan, memproses, menyimpan dan mendistribusikan informasi untuk menunjang pengambilan keputusan dan pengawasan dalam suatu organisasi atau perusahaan[10]. Selain itu sistem informasi juga dapat digunakan untuk membantu dalam menganalisis permasalahan, menggambarkan hal hal yang rumit dan menciptakan produk baru.

\section{Sistem Informasi Perpustakaan}

Sistem informasi perpustakaan adalah suatu sistem di dalam suatu organisasi pelayanan publik yang mempertemukan kebutuhan pengolahan transaksi peminjaman, pengembalian dan perpanjangan buku dan pembuatan laporan harian, bulanan ataupun tahunan guna mendukung operasi, bersifat manajerial dan kegiatan dari suatu organisasi dan menyediakan pihak luar tertentu dengan laporan-laporan yang diperlukan[11]. Sistem informasi perpustakaan adalah proses komputerisasi untuk mengolah data perpustakaan. Mulai dari katalogisasi koleksi, pengolahan data anggota, proses peminjaman dan pengembalian berserta aturan-aturannya yang terdapat didalamnya

\section{Kepuasan}

Kepuasan adalah suatu keadaan yang dirasakan konsumen setelah mengalami suatu kinerja atau hasil yang telah memenuhi berbagai harapannya. Kepuasan adalah perasaan senang atau kecewa seseorang dari perbandingan antara kesannya terhadap kinerja atau hasil suatu produk dengan apa yang diharapkannya[12]. Kepuasan pengguna menggambarkan keselarasan antara harapan seseorang dan hasil yang diperoleh dengan adanya suatu sistem dimana tempat orang tersebut berpartisipasi dalam pengembangan sistem informasi. Kepuasan pengguna sistem informasi merupakan salah satu tolak ukur tingkat keberhasilan penerapan atau penggunaan sebuah sistem informasi, kepuasan tersebut merupakan penilaian yang menyangkut apakah kinerja suatu sistem informasi terbilang baik atau buruk, dan apakah sistem informasi yang digunakan cocok atau tidak dengan tujuan penggunanya.

\section{METODE}

Jenis atau metode yang digunakan dalam penelitian ini adalah menggunakan metode kualitif dengan analisi data secara induktif. Alasan penggunaan analisis data secara induktif karena proses induktif dapat menemukan kenyataan-kenyataan jamak yang terdapat dalam data, selain itu analisis induktif dapat membuat hubungan peneliti dan responden menjadi eksplisit dan dapat dikenal. 


\section{Pemilihan Sampel}

A. Populasi

wilayah generalisasi yang terdiri atas obyek/subjek yang mempunyai kualitas dan karakteristik tertentu yang ditetapkan oleh tim peneliti untuk dipelajari dan kemudian ditarik kesimpulannya[13]. Populasi dalam penelitian ini yaitu petugas yang menggunakan sistem informasi perpustakaan yang terdiri dari 4 orang petugas perpustakaan.

\section{B. Responden Penelitian}

Teknik pengambilan sampel yang di gunakan adalah purposive sampling, dimana sampel dipilih oleh tim peneliti dalam penelitian ini adalah orang yang ahli dalam bidang tersebut. Teknik ini digunakan karena responden yang di pilih merupakan orang yang memang bergelut dibidangnya, sehingga berdasarkan pengamatan di lapangan diambil 2 orang yang benar-benar kompeten dalam menggunakan Sistem Informasi Perpustakaan tersebut.

\section{Metode Pengumpulan Data}

A. Data Primer merupakan data utama yang digunakan dalam penelitian yang diperoleh melalui observasi, wawancara dan survei. Data primer yang digunakan dalam penelitian ini bersumber dari petugas perpustakaan dan anggota perpustakaan yaitu berupa gambaran tentang sistem informasi perpustakaan dengan melakukan wawancara terhadap petugas perpustakaan, selain itu data tentang tingkat kepuasan petugas perpustakaan sebagai pengguna dari sistem informasi perpustakaan dengan memberikan daftar pernyataan berupa kuesioner.

B. Data Sekunder adalah data yang diperoleh peneliti secara tidak langsung yang berupa bukti, catatan atau laporan historis. Selain itu data sekunder yang digunakan diperoleh melalui literatur atau studi pustaka seperti buku, jurnal, prosiding dan laman. Selain itu penulis juga menggunakan dokumentasi data yang berkaitan dengan pengolahan data yang dilakukan sistem informasi perpustakaan yang sesuai dengan topik penelitian.

\section{Instrumen}

Instrumen dalam penelitian digunakan untuk mengumpulkan data, serta akan digunakan untuk melakukan pengukuran dengan tujuan menghasilkan data yang akurat, maka setiap instrumen harus memiliki skala[13]. Skala yang digunakan dalam penelitian ini adalah skala
Likert, skala Likert digunakan untuk mengukur sikap, pendapat dan persepsi seseorang atau selelompok orang tentang fenomena sosial[13]. Pilihan terhadap masing-masing jawaban untuk tanggapan responden atas dimensi kualitas kepuasan diberi skor sebagai berikut:

Tabel 1. Skala Likert

\begin{tabular}{|l|l|l|}
\hline Pilihan Jawaban & Singkatan & Skor \\
\hline Sangat Setuju & SS & $\mathbf{5}$ \\
\hline Setuju & S & $\mathbf{4}$ \\
\hline Netral & N & $\mathbf{3}$ \\
\hline Tidak Setuju & TS & $\mathbf{2}$ \\
\hline Sangat Tidak Setuju & STS & $\mathbf{1}$ \\
\hline
\end{tabular}

Sumber : Sugiyono (2012)[13]

\section{Teknik Analisa Data}

Teknik analisis data yang digunakan adalah deskriptif kualitatif, teknik ini dibutuhkan dalam penelitian ini dikarenakan mempunyai tujuan untuk memberikan gambaran sejauh mana sistem informasi perpustakaan ini dapat dimanfaatkan dan berguna bagi pihak - pihak yang mempunyai kepentingan, khususnya petugas perpustakaan sebagai end-user. Analisis ini juga merupakan suatu analisis yang tidak dinyatakan dalam perhitungan kuantitatif

\section{HASIL}

A. Analisa Sistem

Sistem Informasi Perpustakaan Universitas Merdeka Madiun di buat untuk mempermudah pelayanan terhadap mahasiswa dalam pengelolaan buku. Sistem Informasi ini dibangun dengan berbasis web yang dapat di akses oleh mahasiswa di mana saja dan kapan saja. berikut adalah tampilan dari Sistem Informasi Perpustakaan Universitas Merdeka Madiun. 
1. Halaman Utama pada Sistem Informasi Perpustakaan Universitas Merdeka Madiun

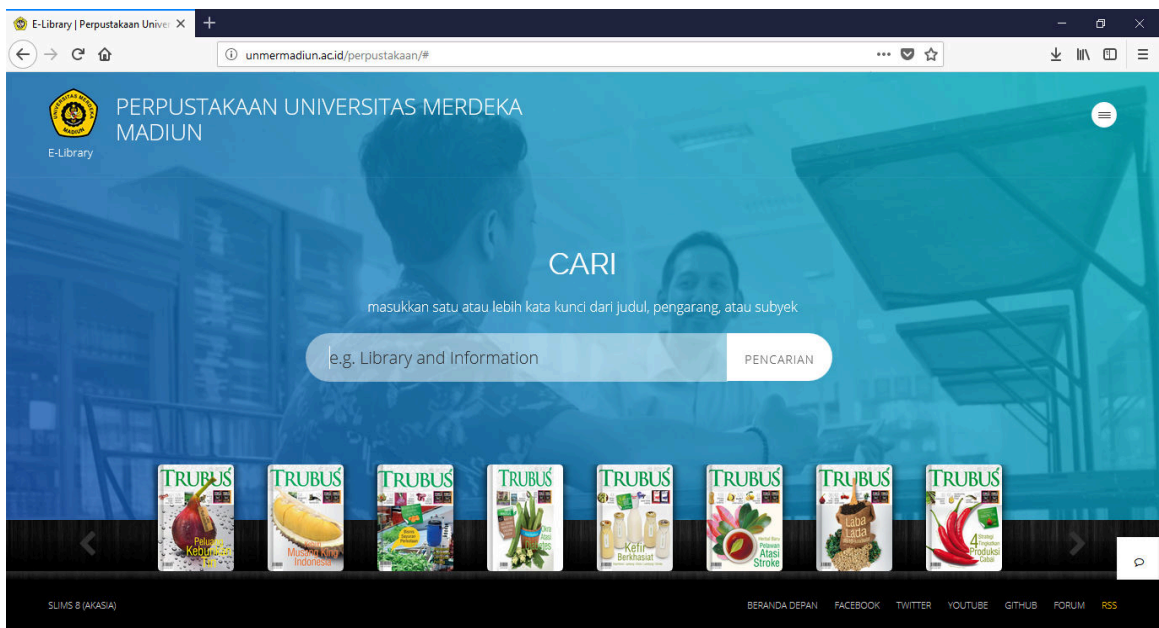

Sumber : Hasil Penelitian (2018)

Gambar 1. Tampilan Halaman Utama Sistem Informasi Perpustakaan

2. Menu Pencarian Buku
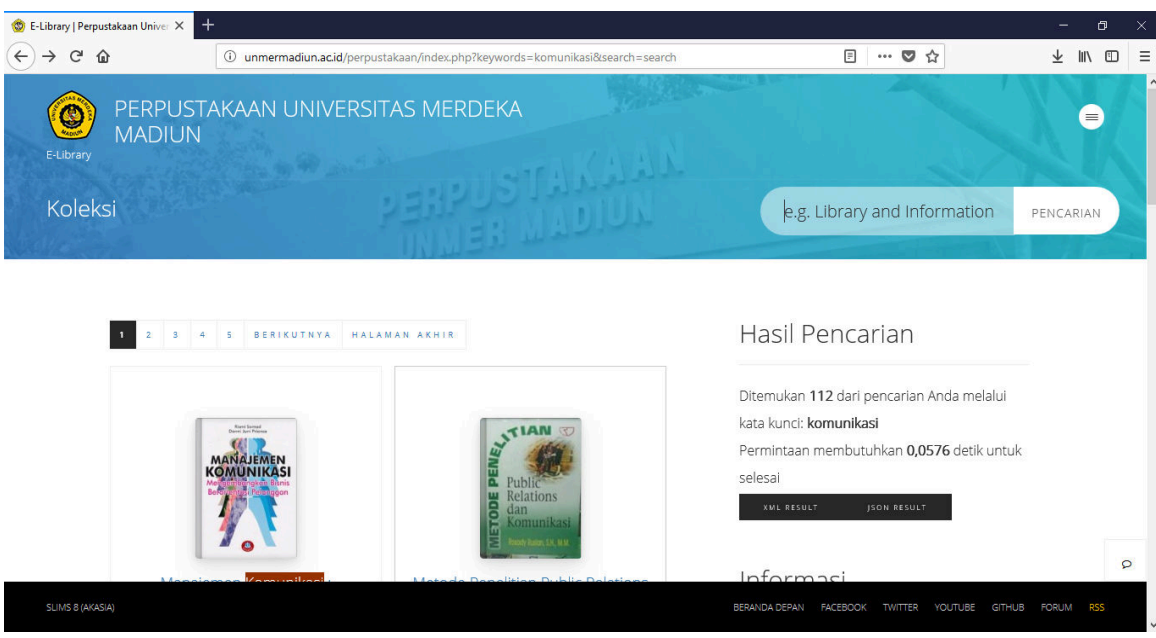

Sumber : Hasil Penelitian (2018)

Gambar 2. Tampilan Menu Pencarian Buku

3. Menu Anggota

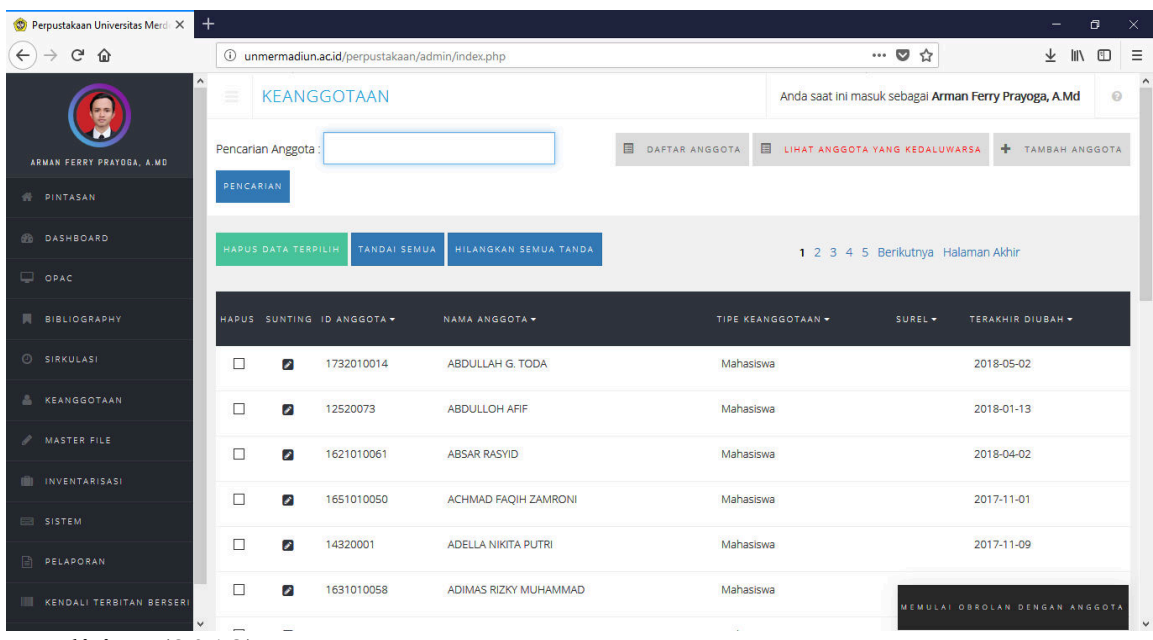

Sumber : Hasil Penelitian (2018)

Gambar 3. Tampilan Menu Anggota 
4. Hasil Pencarian Ketersediaan Buku

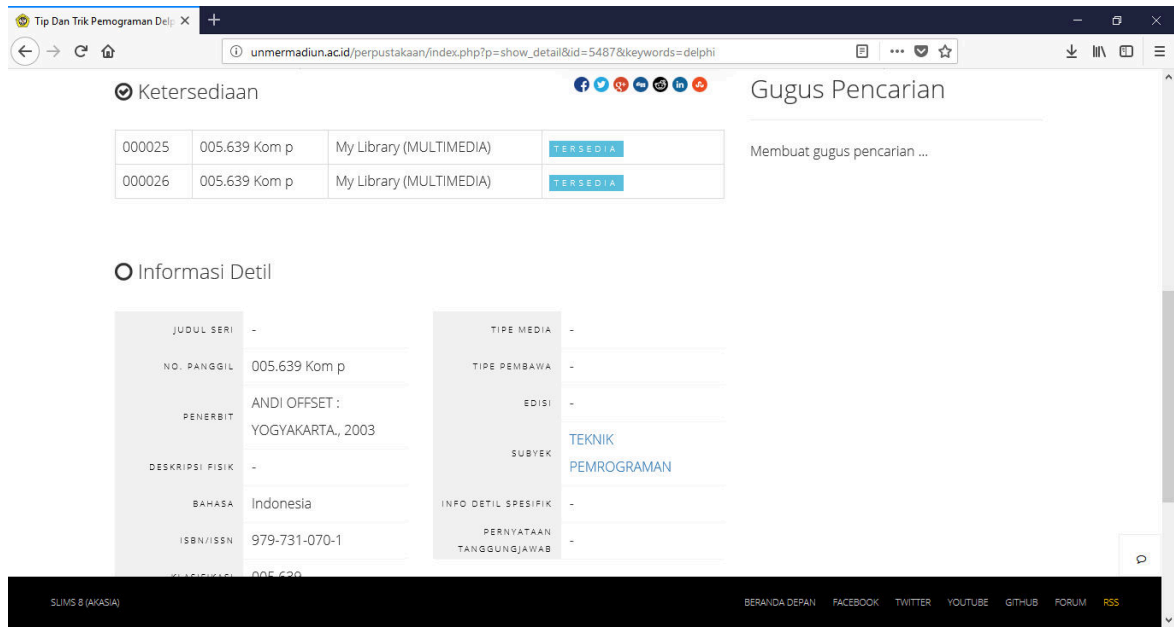

Sumber : Hasil Penelitian (2018)

Gambar 4. Tampilan Halaman Hasil Pencarian Ketersediaan Buku

5. Menu Tentang Sistem Informasi Perpustakaan

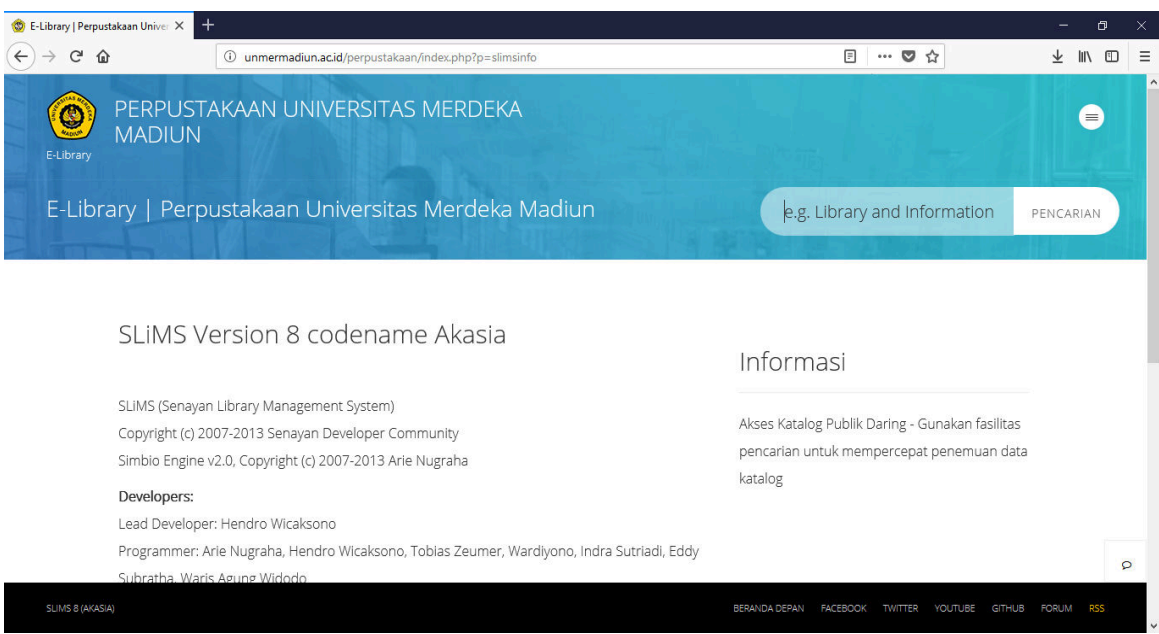

Sumber : Hasil Penelitian (2018)

Gambar 5. Tampilan Tentang Sistem Informasi

B. Hasil Perhitungan dan Analisa Data

Berdasarkan dari hasil kuesioner kepada 10 pengguna Sistem Informasi Perpustakaan dengan menggunakan skala likert untuk mengetahui tinggkat kepuasan mahasiswa terhadap Sistem Informasi Perpustakan sesuai dengan jawaban dan nilainya, maka untuk dapat mengetahui rata-rata tingkat kepuasan dengan rumus

$$
\mathrm{RK}=\frac{\mathrm{JNK}}{\mathrm{NK}}
$$

RK = Rata - Rata Kepuasan

JNK = Jumlah Nilai Kuesioner

$\mathrm{JK} \quad=$ Jumlah Kuesioner
Sedangkan dalam menentukan tingkat kepuasan mahasiswa menggunakan model yang didefinisikan oleh Kaplan dan Norton dengan tinggkatan sebagai berikut :

$$
\begin{array}{ll}
1-1.79 & =\text { Sangat Tidak Puas } \\
1.8-2.59 & =\text { Tidak Puas } \\
2.6-3.39 & =\text { Ragu }- \text { ragu } \\
3.4-4.91 & =\text { Puas } \\
4.2-5 & =\text { Sangat Puas }
\end{array}
$$

Dengan ketentuan diatas, maka akan dapat diperoleh tingkat kepuasan mahasiswa terhadap Sistem Informasi Perpustakaan dalam rata-rata tingkat kepuasan berdasarkan domain yang terdapat pada PIECES Framework sebagai berikut : 


\section{Performance}

Tabel 2. Tabulasi Kuesioner Domain Performance

\begin{tabular}{|l|r|r|r|r|r|}
\hline \multicolumn{7}{|c|}{ PERFORMANCE } \\
\hline RESP. & \multicolumn{1}{|c|}{ SS } & \multicolumn{1}{l|}{ S } & \multicolumn{1}{r|}{ RG } & TS & STS \\
\hline SKOR & 5 & 4 & 3 & 2 & 1 \\
\hline P1 & 2 & 5 & 3 & 0 & 0 \\
\hline P2 & 3 & 3 & 3 & 1 & 0 \\
\hline P3 & 4 & 0 & 4 & 0 & 2 \\
\hline P4 & 0 & 8 & 2 & 0 & 0 \\
\hline JUMLAH & 9 & 16 & 12 & 1 & 2 \\
\hline
\end{tabular}

Sumber : Hasil Penelitian 2018

$$
\begin{gathered}
\mathrm{RK}=\frac{(5 * 9)+(4 * 16)+(3 * 12)+(2 * 1)+(1 * 2)}{40} \\
\mathrm{RK}=\frac{149}{40}=3.75
\end{gathered}
$$

Berdasarkan hasil dari perolehan jumlah rata-rata dari tingkat kepuasan diperoleh 3.75 pada poin kinerja sistem dan bila dipadukan dengan tingkat kepuasan menurut Kaplan dan Norton, maka dapat disimpulkan bahwa tingkat kepuasan mahasiswa terhadap Sistem Informasi Perpustakaan termasuk dalam kategori PUAS. sehingga hal ini menunjukkan indikasi yang positif yaitu mahasiswa sudaj merasa puas dengan kinerja dari Sistem Informasi Perpustakaan Universitas Merdeka Madiun.

\section{Information and Data}

Tabel 3. Tabulasi Kuesioner Domain Information and Data

\begin{tabular}{|l|r|r|r|r|r|}
\hline \multicolumn{7}{|c|}{ Informasi dan Data } \\
\hline RESP. & \multicolumn{1}{|c|}{ SS } & \multicolumn{1}{c|}{ S } & RG & TS & STS \\
\hline SKOR & 1 & 4 & 3 & 0 & 1 \\
\hline P1 & 2 & 5 & 3 & 0 & 0 \\
\hline P2 & 1 & 3 & 0 & 1 & 0 \\
\hline P3 & 4 & 0 & 4 & 0 & 2 \\
\hline P4 & 1 & 5 & 2 & 1 & 0 \\
\hline JUMLAH & 8 & 13 & 9 & 2 & 2 \\
\hline
\end{tabular}

Sumber : Hasil Penelitian 2018

$$
\begin{gathered}
\mathrm{RK}=\frac{(5 * 8)+(4 * 13)+(3 * 9)+(2 * 2)+(1 * 2)}{34} \\
\mathrm{RK}=\frac{125}{34}=3.67
\end{gathered}
$$

Berdasarkan hasil dari perolehan jumlah rata-rata dari tingkat kepuasan diperoleh 3.67 pada domain Informasi serta data sistem dan bila dipadukan dengan tingkat kepuasan menurut Kaplan dan Norton, maka dapat disimpulkan bahwa tingkat kepuasan mahasiswa terhadap Sistem Informasi Perpustakaan termasuk dalam kategori PUAS. sehingga hal ini menunjukkan indikasi yang positif yaitu mahasiswa sudah merasa puas dengan Informasi dan data dari Sistem Informasi Perpustakaan Universitas Merdeka Madiun.

\section{Economic}

Tabel 4. Tabulasi Kuesioner Domain Economic

\begin{tabular}{|l|r|r|r|r|r|}
\hline \multicolumn{7}{|c|}{ Economics } \\
\hline RESP. & SS & \multicolumn{1}{l|}{ S } & RG & TS & STS \\
\hline SKOR & 1 & 4 & 3 & 0 & 1 \\
\hline P1 & 2 & 5 & 3 & 0 & 0 \\
\hline P2 & 1 & 3 & 0 & 1 & 4 \\
\hline P3 & 2 & 1 & 0 & 0 & 0 \\
\hline P4 & 1 & 2 & 3 & 1 & 0 \\
\hline JUMLAH & 6 & 11 & 6 & 2 & 4 \\
\hline
\end{tabular}

Sumber : Hasil Penelitian 2018

$$
\begin{gathered}
\mathrm{RK}=\frac{(5 * 6)+(4 * 11)+(3 * 6)+(2 * 2)+(1 * 4)}{29} \\
\mathrm{RK}=\frac{100}{29}=3.44
\end{gathered}
$$

Berdasarkan hasil dari perolehan jumlah rata-rata dari tingkat kepuasan diperoleh 3.44 pada domain Economic sistem dan bila dipadukan dengan tingkat kepuasan menurut Kaplan dan Norton, maka dapat disimpulkan bahwa tingkat kepuasan mahasiswa terhadap Sistem Informasi Perpustakaan termasuk dalam kategori PUAS. sehingga hal ini menunjukkan indikasi yang positif yaitu mahasiswa sudah merasa puas dengan economic dari Sistem Informasi Perpustakaan Universitas Merdeka Madiun.

\section{Control and Security}

Tabel 5. Tabulasi Kuesioner Domain Control and Security

\begin{tabular}{|l|r|r|r|r|r|}
\hline \multicolumn{7}{|c|}{ Control and Security } \\
\hline RESP. & \multicolumn{1}{|c|}{ SS } & \multicolumn{1}{l|}{ S } & \multicolumn{1}{|r|}{ RG } & TS & STS \\
\hline SKOR & 1 & 4 & 3 & 0 & 1 \\
\hline P1 & 2 & 5 & 3 & 0 & 0 \\
\hline P2 & 1 & 3 & 0 & 1 & 0 \\
\hline P3 & 4 & 0 & 4 & 0 & 2 \\
\hline P4 & 1 & 5 & 2 & 1 & 0 \\
\hline JUMLAH & 8 & 13 & 9 & 2 & 2 \\
\hline
\end{tabular}

Sumber : Hasil Penelitian 2018

$$
\begin{gathered}
\mathrm{RK}=\frac{(5 * 8)+(4 * 13)+(3 * 9)+(2 * 2)+(1 * 2)}{34} \\
\mathrm{RK}=\frac{125}{34}=3.67
\end{gathered}
$$

Berdasarkan hasil dari perolehan jumlah ratarata dari tingkat kepuasan diperoleh 3.67 pada domain Control dan security sistem dan bila dipadukan dengan tingkat kepuasan menurut Kaplan dan Norton, maka dapat disimpulkan bahwa tingkat kepuasan mahasiswa terhadap Sistem Informasi Perpustakaan termasuk dalam 
kategori PUAS. sehingga hal ini menunjukkan indikasi yang positif yaitu mahasiswa sudah merasa puas dengan Control dan security dari Sistem Informasi Perpustakaan Universitas Merdeka Madiun.

\section{Efficiency}

Tabel 6. Tabulasi Kuesioner Domain Efficiency

\begin{tabular}{|l|r|r|r|r|r|}
\hline \multicolumn{7}{|c|}{ Efficiency } \\
\hline RESP. & SS & S & RG & TS & STS \\
\hline SKOR & 5 & 4 & 3 & 0 & 0 \\
\hline P1 & 3 & 5 & 3 & 0 & 0 \\
\hline P2 & 9 & 1 & 0 & 0 & 0 \\
\hline P3 & 4 & 0 & 0 & 0 & 0 \\
\hline P4 & 8 & 0 & 0 & 1 & 0 \\
\hline JUMLAH & 24 & 6 & 3 & 1 & 0 \\
\hline
\end{tabular}

Sumber : Hasil Penelitian 2018

$$
\begin{gathered}
\text { RK }=\frac{(5 * 24)+(4 * 6)+(3 * 3)+(2 * 1)+(1 * 0)}{34} \\
\text { RK }=\frac{155}{34}=4.55
\end{gathered}
$$

Berdasarkan hasil dari perolehan jumlah ratarata dari tingkat kepuasan diperoleh 4.55 pada domain Efficiency sistem dan bila dipadukan dengan tingkat kepuasan menurut Kaplan dan Norton, maka dapat disimpulkan bahwa tingkat kepuasan mahasiswa terhadap Sistem Informasi Perpustakaan termasuk dalam kategori SANGAT PUAS. sehingga hal ini menunjukkan indikasi yang positif yaitu mahasiswa sudah merasa puas dengan Efficiency dari Sistem Informasi Perpustakaan Universitas Merdeka Madiun.

\section{Service}

Tabel 7. Tabulasi Kuesioner Domain Efficiency

\begin{tabular}{|l|r|r|r|r|r|}
\hline \multicolumn{7}{|c|}{ Service } \\
\hline RESP. & SS & S & RG & TS & STS \\
\hline SKOR & 2 & 4 & 3 & 1 & 1 \\
\hline P1 & 3 & 5 & 3 & 0 & 0 \\
\hline P2 & 1 & 1 & 0 & 1 & 3 \\
\hline P3 & 4 & 0 & 0 & 0 & 1 \\
\hline P4 & 1 & 0 & 0 & 1 & 0 \\
\hline JUMLAH & 9 & 6 & 3 & 2 & 4 \\
\hline
\end{tabular}

Sumber : Hasil Penelitian 2018

$$
\begin{gathered}
\mathrm{RK}=\frac{(5 * 9)+(4 * 6)+(3 * 3)+(2 * 2)+(1 * 4)}{24} \\
\mathrm{RK}=\frac{86}{24}=3.58
\end{gathered}
$$

Berdasarkan hasil dari perolehan jumlah ratarata dari tingkat kepuasan diperoleh 3.58 pada domain Service sistem dan bila dipadukan dengan tingkat kepuasan menurut Kaplan dan Norton, maka dapat disimpulkan bahwa tingkat kepuasan mahasiswa terhadap Sistem Informasi Perpustakaan termasuk dalam kategori PUAS. sehingga hal ini menunjukkan indikasi yang positif yaitu mahasiswa sudah merasa puas dengan Service dari Sistem Informasi Perpustakaan Universitas Merdeka Madiun.

\section{KESIMPULAN}

Berdasarkan hasil perhitungan data dan analisa terhadap kepuasan mahasiswa dalam menggunakan sistem informasi perpustakaan dengan tujuan untuk mengevaluasi dan menganalisa kekuatan dan kelemahan yang terdapat pada sistem informasi perpustakaan, maka dapat disimpulkan menjadi beberapa bagian, yaitu :

1. Berdasarkan metode analisis kerangka kerja PIECES yang terdiri dari Performance, Information and data, Economics, Control and Security, Efficiency, dan Service dalam mengevaluasi sistem informasi perpustakaan Universitas Merdeka Madiun didapatkan nilai tingkat kepuasan mahasiswa dari masing-masing domain yaitu domain Performance memperoleh skor 3,72 dengan predikat PUAS, domain Information and Data memperoleh skor 3,67 dengan predikat PUAS, domain Economics memperoleh skor 3.44 dengan predikat PUAS, domain Control and Security memperoleh skor 3.67 dengan predikat PUAS, domain Efficiency memperoleh skor 4,55 dengan predikat SANGAT PUAS dan domain Service memperoleh skor 3.58 dengan predikat PUAS.

2. Sistem Informasi Perpustakaan Universitas Merdeka Madiun berdasarkan kerangka kerja PIECES sudah mampu memberikan kepuasan kepada Mahasiswa.

\section{DAFTAR PUSTAKA}

[1] A. Supriyatna Jurusan Manajemen Informatika AMIK BSI Karawang J1 Ahmad Yani No, "PERPUSTAKAAN DENGAN MENGGUNAKAN PIECES FRAMEWORK," J. Pilar Nusa Mandiri, vol. XI, no. 1, 2015.

[2] A. Supriyatna and V. Maria, "PENGUKURAN TINGKAT KEPUASAN PENGGUNA SISTEM INFORMASI DJP ONLINE PELAPORAN SPT PAJAK," Pros. SNATIF, vol. 0, no. 0, pp. 147154, Sep. 2017.

[3] Khanna Tiara, SISTEM MONITORING INVENTORY CONTROL PADA CV. CIHANJUANG BUDI JAYA. STMIK RAHARJA, 2014. 
[4] E. Fatmawati, "Technology Acceptance model (TAM) untuk menganalisis penerimaan terhadap sistem informasi di perpustakaanM INFORMASI PERPUSTAKAAN," IQRA' $J$. Perpust. dan Inf., vol. 9, no. 1, May 2015.

[5] I. Hafid, I. E. S. M.Eng, and M. K. Riska A., "PERANCANGAN SISTEM INFORMASI PERPUSTAKAAN DIGITAL (DIGITAL LIBRARY) DENGAN METODE AGILE PADA MTSN TANDIKAT BERBASIS WEB MENGGUNAKAN PHP MySQL," Abstr. Undergraduate, Fac. Educ. Bung Hatta Univ., vol. 2, no. 2, Jun. 2015.

[6] L. Nulhakim, N. Azizah, and M. T. Ajija, "Sistem Informasi Monitoring Inventory Dengan Analisa PIECES Pada PT Care Spundbond," SENSITEK, vol. 1, no. 1, pp. 480-485, Jul. 2018.

[7] D. Nurulita and S. Darnoto, "PROSIDINGSEMNAS \&amp; CALL FOR PAPERS ANALISIS SISTEM INFORMASI INOVASI PSC (PUBLIC SAFETY CENTER) 119 DENGAN METODE PIECES DI DINAS KESEHATAN KA-BUPATEN BOYOLALI," Pros. - SEMNAS CALL Pap.

[8] T. Sutabri, Sistem Informasi Manajemen, (Edisi I). Yogyakarta: Andi Offset, 2007.

[9] H. Jogiyanto, Metodologi Penelitian Sistem Informasi. Yogyakarta: Andi Offset, 2008.

[10] R. Pamungkas, "Perancangan Sistem Informasi Pembayaran Administrasi SMK Negeri 1 Jiwan," INTENSIF, vol. 1, no. 2, p. 129, Aug. 2017.

[11] Perpustakaan., Program Studi Ilmu Perpustakaan. Fakultas Sastra: USU. Medan: Gedung dan Perlengkapan, 2007.

[12] P. Kotler, Marketing Management, International Edition. New Jersey: Prentice Hall, Inc.

[13] Sugiyono, Metode Penelitian Kuantitatif, Kualitatif dan $R$ \& D. Bandung. Bandung: CV.Alfabeta, 2012. 